Revista de Ciencias Sociales - Número 68 (2016) - Páginas 63-104

Análisis transdisciplinar de la igualdad de género desde lo...

\title{
ANÁLISIS TRANSDISCIPLINAR DE LA IGUALDAD DE GÉNERO DESDE LO SOCIOECONÓMICO, EDUCATIVO, JURÍDICO Y AXIOLÓGICO
}

\author{
TRANSDISCIPLINARY ANALYSIS OF THE GENDER \\ EQUALITY FROM THE PERSPECTIVE ECONOMIC, \\ EDUCATIONAL, LEGAL AND AXIOLOGICAL
}

\author{
ELENA RICARDO OCHOA* \\ Universidad de Holguín (Cuba) \\ ericardo@ict.uho.edu.cu \\ YAMILKA PINO SERA** \\ Universidad de Holguín (Cuba) \\ ypino@ict.uho.edu.cu
}

\section{Resumen}

En la Cuba de hoy, amparado por normas jurídicas, se perciben relevantes transformaciones relacionadas con las mujeres y las relaciones de género en varios ámbitos de la sociedad, tales como: la significativa disminución de las desigualdades entre mujeres y hombres en cuanto a educación, participación laboral y sociopolítica a todos los niveles; la separación entre

* Licenciada en Filosofía e Historia. Profesora Auxiliar, profesora del Departamento de Filosofía de la Universidad de Holguín, Cuba. Artículo recibido el 8 de junio de 2016 y aceptado el 4 de julio de 2016.

* Licenciada en Derecho y Máster en Ciencias Sociales y Axiología. Profesora auxiliar del Departamento de Filosofía de la Universidad de Holguín, Cuba.

Revista de Ciencias Sociales - Número 68 (2016) - Universidad de Valparáíso - ISSN 0716-7725-Valparáiso, Chile 
sexualidad y reproducción, el derecho a controlar la fecundidad; y la superación de algunas concepciones y prejuicios que estigmatizaban a la mujer. Sin embargo, aún persisten y se reproducen ciertas problemáticas que pueden obstaculizar la realización plena de la igualdad en las relaciones de género. El presente artículo tiene como objetivo realizar un análisis transdisciplinar de la igualdad en las relaciones de género en Cuba, con una mirada desde lo socioeconómico, educativo, jurídico y axiológico.

\section{Palabras clave}

Género, legislación, educación, economía, valores.

\section{Abstract}

Nowadays in Cuba, protected by legal norms, there are relevant transformations related to women and gender relations in various areas of society such as: the significant reduction of inequalities between women and men in education, labor and sociopolitical participation at all levels; the separation between sexuality and reproduction, the right to control fertility; and the overcoming of some conceptions and prejudices that stigmatize women. However, certain problems still persist and that may hinder the full realization of equality in gender relations. This article aims to make an interdisciplinary analysis of equality in gender relations in Cuba from the socio-economic, educational, legal and axiological viewpoint.

\section{Keywords}

Gender, legislation, education, economy, values.

\section{INTRODUCCIÓN}

Los años de las décadas de 1960 y 1970, marcan importantes hitos en el proceso de emancipación de las mujeres, en un contexto de crisis y cambios del pensamiento androcéntrico, ascenso de movimientos sociales, e impetuoso renacer de las corrientes intelectuales y políticas feministas.

Teóricos(as) feministas, fundamentalmente, profundizan en las relaciones de género, a partir de su interés en el desarrollo de una comprensión crítica de la sociedad, orientada a cambiar el mundo social en direcciones que posibilitaran mayores espacios de libertad, igualdad y justicia para los sujetos femeninos.

Facultad de Derecho y Ciencias Sociales - Universidad de Valparaíso - Chile 
Se visibilizan realidades que afectan a hombres y mujeres, insuficientemente reconocidas por la sociedad y las ciencias sociales, contribuyendo con ello a revolucionar las concepciones predominantes sobre las relaciones de género.

El concepto género, denomina la construcción sociocultural de las identidades diferenciadas de mujeres y hombres. Consiste en la adscripción de identidades, creencias, sentimientos, conductas, funciones, tareas, actitudes, responsabilidades, roles y valores diferenciales que la sociedad establece para cada uno de los sexos, los que se expresan como desigualdades sociales ${ }^{1}$.

Diversas normativas legales aprobadas a partir de mediados del siglo XX, en mucho le deben a la pujanza de los movimientos feministas y por la igualdad de género. Entre esas normativas sobresalen la Declaración y Plataforma de Acción de Beijing, la Convención sobre la Eliminación de Todas las Formas de Discriminación Contra las Mujeres (CEDAW), la Convención Sobre los Derechos de la Niña, y la Convención Interamericana Sobre la Prevención, Castigo, y Erradicación de la Violencia.

Desde 1995, la ONU validó el concepto de género que las teóricas(os) feministas habían desarrollado para evidenciar que lo que consideramos femenino y masculino, es el resultado de una construcción sociocultural en momentos históricos concretos, y que se expresa en relaciones jerárquicas de poder.

Con todo, el análisis de las relaciones de género es una ardua tarea, que ha generado no pocos equívocos. Algunas vertientes de feminismo, reducen los problemas de género a los de las mujeres, y estas aparecen en ocasiones como sujetos homogéneos. Asimismo, conectan la subordinación, discriminación e infravaloración del sujeto femenino a un tipo de organización social supuestamente estática en el tiempo y universal: el patriarcado.

En la acepción clásica de categoría patriarcado, se buscan las claves para comprender las relaciones de género. Ello tiene serias implicaciones epistemológicas, al configurar un enfoque universalista,

1. STAFF, Mariblanca: "La perspectiva de género desde el Derecho”, Rivera, Staff \& Asociados, 2000 (soporte digital).

Revista de Ciencias Sociales - Número 68 (2016) - Universidad de Valparáíso - ISSN 0716-7725-Valparáiso, Chile 
donde hombres, mujeres, formas de familia, entre otros aspectos sociales aparecen al margen de su contexto histórico-cultural y de las diversas relaciones que se articulan en este.

La desconstrucción de las relaciones de género implica asumir que ellas se producen entre sujetos con igual y diferente sexo, identidad y orientación sexual; situados diversamente en el entramado de grupos y clases sociales, generaciones y etnias.

Todo ello dentro de una región, comunidad residencial, y sociedad que puede estar en relaciones de simbiosis, o de conflicto, con otras sociedades circundantes, pero siempre bajo el influjo de la intersección de procesos sociales internos y externos.

El cambio es consustancial a toda sociedad. La mayoría de las sociedades no son patriarcales, en el sentido histórico del término que alude a una institución social cuya configuración inicial obedeció a las necesidades, circunstancias y relaciones presentes en diversas sociedades precapitalistas.

En las sociedades actuales las relaciones de poder, dominación/ subordinación entre los sexos se realiza bajo estructuras, condiciones y procesos sociales específicos vigentes en las sociedades contemporáneas. Como ha observado Boron la opresión de la mujer está actualmente marcada por la creciente mercantilización del espacio privado y la incorporación cada vez mayor de la mujer al mercado de trabajo ${ }^{2}$.

Los cambios sociales, científicos y tecnológicos acaecidos a lo largo del siglo XX profundizan el proceso de entrada de amplios segmentos de las mujeres a los cada vez más competitivos mercados de trabajo, verificándose por un lado el ascenso del grado de instrucción, especialización y calificación, especialmente de algunos sujetos femeninos, y por otro un acentuado grado de desigualdad, marginación y exclusión signados por la pertenencia a territorio, clase, etnia que afecta a hombres y mujeres.

Los cambios socioeconómicos, demográficos, políticos, culturales, entre otros, repercuten en el ámbito familiar. $\mathrm{Al}$ respecto, en numerosas sociedades la familia experimenta cambios entre los que se destacan

2. BORON, Atilio. Tras el búho de Minerva. Editorial de Ciencias Sociales, La Habana, 2003. Págs. 45 y ss.

Facultad de Derecho y Ciencias Sociales - Universidad de Valparaíso - Chile 
una reducción del tamaño medio de las familias, el incremento de la jefatura femenina en los diversos tipos de familia; la coexistencia de familias nucleares, reconstituidas, ampliadas, y monoparentales en su mayoría maternas.

Dichos cambios, entre otros, conllevan transformaciones en las relaciones de género en el ámbito familiar, observándose procesos de desestructuración/nuevas estructuraciones de las relaciones de poder entre los sexos, y de algunos roles, prejuicios, actitudes sociales, y valores culturalmente construidos.

Sin embargo, existen significativas continuidades en las relaciones de género tales como la pervivencia de algunos esquemas referenciales configurados en torno a los sexos, cuya transmisión cultural corre a cuenta de hombres y mujeres; en procesos cada vez más abiertos y contradictorios de socialización y educación, en los que la familia continúa siendo un agente principal, al tiempo que se refuerza el papel de los grupos formales e informales, los medios de comunicación, la iglesia, la comunidad, las escuelas, centros laborales, entre otros agentes socializadores.

Otras continuidades en las relaciones de género apuntan a cierta sobrerrepresentación de las mujeres en el cumplimiento de funciones doméstico familiares, y en los grupos sociales en situaciones socioeconómicas y culturales más desventajosas.

Existen no pocas situaciones individuales, grupales, familiares, entre otras, que puede obstaculizar, frenar, e incluso hacer inefectivas a nivel microsocial, legislaciones nacionales e internacionales y políticas públicas encaminadas a contribuir al ansiado logro de la igualdad en las relaciones de género.

La comprensión creadora, transdisciplinar, es una exigencia que nos impone los múltiples condicionamientos, el estado real y desafíos de las relaciones de género. Solo desde ella podremos aprehender a estas últimas en sus determinaciones esenciales y con ello superar las mistificaciones y reduccionismos teórico-culturales que la han encubierto históricamente.

El presente artículo tiene como objetivo realizar un análisis transdisciplinar de la igualdad en las relaciones de género en Cuba, con una mirada desde lo socioeconómico, educativo, jurídico y axiológico. Dicho análisis, por supuesto, es aproximativo e incompleto.

Revista de Ciencias Sociales - Número 68 (2016) - Universidad de Valparáíso - ISSN 0716-7725-Valparaíso, Chile 


\section{DESARROLLO}

El Derecho es una de las áreas de las ciencias sociales, que tiene como protagonista al ser humano, en cuanto sujeto/a capaz de adoptar determinadas actitudes ante el proceso histórico social. Es también, uno de los aspectos que se afectan con mayor rapidez ante los procesos de cambios vertiginosos que se producen a nivel mundial y que conducen, inevitablemente, a "nuevas formas de relación” económica, política, social, cultural, familiar y personal'.

Nadie pone en duda que el Derecho juega un factor importante para que las mujeres puedan lograr la consolidación y el respeto de sus derechos humanos y constitucionales, porque es un mecanismo mediante el cual se puede involucrar a los hombres y a las mujeres de leyes en la promoción, creación y aplicación de leyes desde la perspectiva de género, es decir, a través de una conciencia no discriminatoria y en la defensa de los derechos humanos de las mujeres, desde la realidad jurídica vigente ${ }^{4}$.

Veamos lo que la abogada puertorriqueña, Ixa López Palau, señala respecto a lo llamado por la misma como "castración jurídica": "Las leyes han sido las aliadas más importantes del sistema patriarcal. Por medio de ellas se mantiene y afianza el poder de los hombres sobre las mujeres"

Actualmente esto ha cambiado, aunque no del todo. Además, es evidente que las realidades y prácticas jurídicas y sociales son mucho más complejas y diversas. Es imprescindible responder a un desarrollo más armónico y real de las relaciones de género y articular propuestas de desarrollo más justas y humanas, a partir de un Derecho renovado, integrador y equitativo.

Llegado este punto es importante reflexionar acerca de que en ocasiones las propias mujeres contribuyen más o menos conscientemente

3. STAFF, Mariblanca: ob. cit.

4. Ídem.

5. LÓPEZ, Ixa: Violencia contra la Mujer. Ediciones Lego, San Juan, Puerto Rico 1999. Pág. 24.

Facultad de Derecho y Ciencias Sociales - Universidad de Valparaíso - Chile 
a la reproducción de prejuicios, estereotipos, roles, actitudes y comportamientos de una cultura sexista que se intenta superar, desde el indudable papel que juegan en los procesos socializadores y educativos.

En el análisis de la situación jurídica de las mujeres, la tendencia ha sido la de acudir al estudio formal de los textos legales existentes y se concluye que las mujeres gozan de igualdad de derechos con relación a los hombres, porque así se establece en la Constitución, sin embargo, cuando se va al análisis integral y diferenciador del sistema jurídico, se encuentra una realidad muy diferente.

Dicho en otras palabras, existe igualdad en la ley y desigualdad en la práctica; pues a menudo no encontramos una normativa penal que ampare a la mujer que pretenda hacer una denuncia formal ante el órgano competente, por haber sido objeto de una violación de sus derechos como persona y mujer en cualquier ámbito de la vida social.

Además no existe aún un cambio total al nivel subjetivo de los hombres que imparten justicia, y más triste aún es reconocer que en algunas de las mujeres juristas.

Es necesario el diseño de políticas que, desde diferentes ámbitos, contribuyan a generar acciones a favor de la mujer, a cambiar los estereotipos de género y a definir un nuevo concepto de justicia para tratarlos/as iguales.

Estas políticas sociales han de ser reflexivas, rigurosas y críticas, de forma tal que al asumir sus compromisos jurídico-sociales, respondan a su vez a los valores oficiales o instituidos y sobre todo a los valores subjetivos de las mujeres y hombres no sexistas.

En este artículo las autoras asumen lo planteado por el filósofo cubano Fabelo en cuanto a que: "en cualquier ámbito social es posible encontrar, además del sistema objetivo de valores, una diversidad de sistemas subjetivos y un sistema socialmente instituido" ", dado que es un fenómeno complejo, pues según sea la índole de las relaciones que se establecen, así serán los valores que primarán, pues en toda relación humana están presente los valores de una forma concatenada, por lo

6. $\quad$ FABELO, José R.: Los valores y sus desafíos actuales. Editorial José Martí, La Habana, 2011. Pág. 5.

Revista de Ciencias Sociales - Número 68 (2016) - Universidad de Valparáíso - ISSN 0716-7725-Valparaíso, Chile 
que en estas encontramos un vínculo estrecho entre el sistema objetivo, subjetivo e instituido de los valores.

Las autoras entienden que las relaciones de género deben estar permeadas de valores como la responsabilidad, igualdad, equidad, honestidad, solidaridad, humanismo, libertad, justicia, entre otros.

Conviene integrar en todo análisis acerca de la igualdad de género la cuestión de la diversa posición que hombres y mujeres pueden ocupar en la división social del trabajo, en las relaciones de propiedad y en el diferente acceso a la riqueza social; todo lo cual conlleva la formación de grupos y estratos sociales en los que se visualizan unos y otros, con la consiguiente mayor o menor posibilidad para satisfacer sus necesidades y para dominar/discriminar, o ser dominados/discriminados por otros.

A lo largo del Siglo XX, condicionado por los cambios económicos, tecnológicos, sociales, y el indudable papel del ascenso de los movimientos sociales, especialmente feministas, se verifican mejorías en la situación socioeconómica y educativa de algunos segmentos de hombres y mujeres en todo el mundo. Ello no ocurre de manera homogénea al interior y entre las diversas sociedades, ni en todos los casos ha traído consigo el deseable mejoramiento de la igualdad en las relaciones de género.

Los procesos de transición demográfica, la creciente urbanización, la privatización, incremento del desempleo y la precariedad laboral, la desigual distribución de la riqueza social que conlleva una drástica reducción de los presupuestos destinados a la salud, a la educación y a otros servicios sociales, el incremento de la pobreza y de los flujos migratorios internos e internacionales, entre otros factores inciden negativamente en la igualdad de género.

En 1995, el Informe del Programa de las Naciones Unidas sobre el Desarrollo dio cuenta de que "más de dos terceras partes de los 900 millones de personas analfabetas adultas en el mundo son mujeres; la mayoría de los 130 millones de infantes que carecen de acceso a la escuela primaria son niñas; —las mujeres adultas sufren de desnutrición en mayor cuantía que los hombres, persisten altas tasas de mortalidad materna en varias regiones del mundo;- en los países en desarrollo representan sólo la séptima parte de los funcionarios administrativos y

Facultad de Derecho y Ciencias Sociales - Universidad de Valparaíso - Chile 
ejecutivos; - representan el $10 \%$ de los parlamentos, el 6\% de los puestos ministeriales y el $14 \%$ de los puestos administrativos"

Este informe contribuye a la expansión del interés sobre otras problemáticas que afectan con particular fuerza a las mujeres como son la discriminación jurídica y laboral, menor control sobre los recursos, sobrecarga sobre las mujeres de los roles domésticos; en circunstancias de menor control de los recursos, baja remuneración a las féminas, ausencia de protección social y legal, disminución de salarios reales por el aumento de los precios, afectaciones a los servicios de salud y educación, y en general la acentuación de la feminización de la pobreza bajo los efectos negativos de las políticas neoliberales. A partir de las estas realidades en las relaciones de género el PENUD introduce dos innovaciones metodológicas significativas: el Índice de Desarrollo de la Mujer (IDM), y el Índice de Potenciación de la Mujer (IPM) ${ }^{8}$.

El Índice de Desarrollo de la Mujer (IDM), al igual que el Índice de Desarrollo Humano (IDH) mide el grado de progreso en dimensiones básicas como desarrollo económico; nivel de educación; estado de salud; acceso a servicios básicos, a la cultura y a la comunicación; recursos para educación y salud; medio ambiente, entre otras. Pero el IDM, posteriormente tratado como Índice de Desarrollo de Género (IDG), incorpora la desigualdad entre hombres y mujeres. El Índice de Potenciación de la Mujer (IPM), ulteriormente denominado índice de Potenciación de Género (IPG), mide la participación activa de las mujeres y hombres en los ámbitos económico y político.

En 1996, el informe presentado por La Comisión Económica para América Latina (CEPAL) subraya que la inserción laboral de las mujeres se produce, mayoritariamente, en microempresas, trabajo doméstico, servicios comunales, sociales y personales y en un bajo porcentaje en el sector formal de la economía. Los ingresos de las mujeres ocupadas en el sector formal de la economía representaban el $74 \%$ del ingreso de los hombres en ese mismo sector; mientras que en el sector

7. ZABALA, María del Carmen: Jefatura femenina de hogar, pobreza urbana y exclusión social: una perspectiva desde la subjetividad en el contexto cubano. CLACSO, Argentina, 2009. Pág. 49.

8. Ídem.

Revista de Ciencias Sociales - Número 68 (2016) - Universidad de Valparáíso - ISSN 0716-7725-Valparaíso, Chile 
informal las mujeres percibían el $52 \%$ del ingreso de los hombres. En los informes de 1997 y 1999 de la Organización Internacional del trabajo (OIT) se alude, respectivamente, a la leve reducción de la diferencia de ingresos de ambos sexos en las ocupaciones informales (4,7\%); y a que las mujeres necesitan mayor cantidad de años de estudios para acceder a las mismas oportunidades ocupacionales que los hombres ${ }^{9}$.

Las desigualdades de género en aspectos como integración al ámbito laboral en ramas y tipos de actividad económica, y retribuciones recibidas no es una cuestión baladí. Se trata de dos aspectos que tienen que ver con el la menor o mayor posibilidad de satisfacer necesidades; con el acceso a bienes y recursos de cualquier clase que generan poder sobre objetos, bienes y sobre actores, inseparable esto de procesos de significación, dominación y legitimación; y además con la posibilidad real de cumplir adecuadamente con importantes funciones jurídica y socioculturalmente atribuidas, no sin contradicciones, a hombres y mujeres.

En los marcos del presente trabajo hemos llamado la atención acerca de la complejidad de las relaciones de género, y la necesidad de superar visiones reduccionistas que tienen como una de sus manifestaciones el hablar de hombres y mujeres como integrantes de grupos homogéneos según sexo, obviando diferenciaciones socioeconómicas, clasistas, culturales y otras entre las propias mujeres y entre los hombres.

Los estudios de Escribá y Parella ${ }^{10}$ aportan evidencias de que la existencia de un modelo de acumulación basado en la flexibilidad, la preeminencia del factor terciario de la economía, el aumento del nivel educativo de la población económicamente activa, la incapacidad de generar empleos adecuados al crecimiento del nivel de instrucción y calificación, y de la población en edad laboral trae como consecuencia

9. DE LA CRUZ, Silvia: "Dualidad social y sexual”. En: Red Fundamentos en Humanidades, Argentina, 2005. Págs. 138 y ss.

10. ESCRIBÁ, Ángeles: “¿Empleadas de por vida? Peruanas en el servicio doméstico en Barcelona”. En: Revista Papers, Universidad de Barcelona, 2000.

Págs.327 y ss. PARELLA, Sonia: "El trasvase de las desigualdades de clase y etnia entre mujeres: los servicios de proximidad”. En: Revista Papers, Universidad de Barcelona, 2000. Págs. 275 y ss.

Facultad de Derecho y Ciencias Sociales - Universidad de Valparaíso - Chile 
el incremento de los despidos y del desempleo, la proliferación de contratos de trabajo a tiempo determinado y de la economía informal.

En estas circunstancias tiene lugar la discriminación por razones de sexo, clase, etnia. Los inmigrantes, en su mayoría mujeres, quedan relegados a las actividades más precarias, sucias y mal pagadas por parte de hombres y mujeres de clase media y alta, en ocasiones bajo formas de economía informal, lo que ha dado lugar a la llamada etnoestratificación del mercado laboral. Las leyes normalizan la discriminación institucional pues definen las posibilidades de inserción laboral de los inmigrantes (hombres y mujeres) hacia aquellas actividades poco cualificadas y de peores condiciones como respuesta a la demanda de mano de obra barata para servicios desvalorizados socialmente por la población autóctona, entre ellos los servicios de proximidad, al tiempo que ofrecen mayores posibilidades a las mujeres inmigrantes que a los hombres en similar situación para regularizar su situación jurídica ${ }^{11}$.

Es frecuente que en numerosos sociedades exista un sistema de normas y contranormas. De un lado se aprueban y ratifican normativas legales internacionales que refrendan la igualdad de género, y de otro legislaciones nacionales, prácticas sociales, y actitudes, prejuicios, valores y comportamientos culturales avanzan escasamente o generan en la práctica una situación de género que difícilmente puede contribuir a mayores grados de igualdad.

Es por ello, entre otras razones, que también aceptamos la siguiente propuesta de Alda Facio, abogada feminista, experta en Derecho Internacional: "ni siquiera nos deben importar, para efectos de la reconceptualización de la igualdad, cuáles diferencias son biológicas y cuáles son construidas por el género, sino que debemos concentrarnos en crear una igualdad de resultados para todas las personas que parten precisamente, de que hoy un mayor número de personas vivimos con grandes desigualdades y que esas desigualdades deben ser el punto de partida y no llegada de las leyes"12.

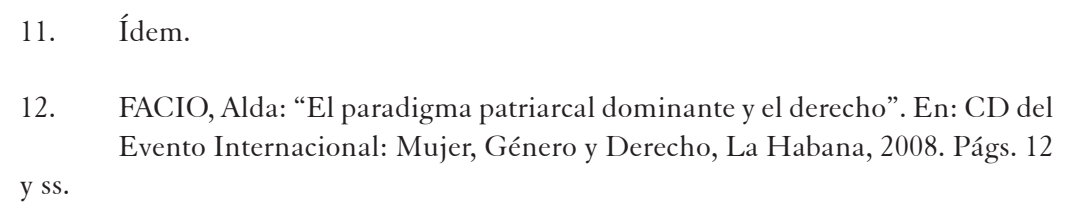


En el año 1946 surge la Comisión de la Condición Jurídica y Social de la Mujer, por el órgano establecido en el Sistema de Naciones Unidas para analizar y formular recomendaciones de políticas a fin de mejorar la condición jurídica de las Mujeres. Posteriormente, surgen varios INSTRUMENTOS con carácter vinculante, tales como: en 1952 —Convención sobre los Derechos Políticos de la Mujer, 1967Declaración sobre la Eliminación de la Discriminación Contra la Mujer. No vinculante, 1979 —Convención sobre la Eliminación de todas las Formas de Discriminación Contra la Mujer (CEDAW).

El marco de desarrollo de este término tiene su génesis en la Convención para la eliminación de todas las formas de discriminación contra la mujer, aprobada por la ONU en 1979 y que entró en vigor en 1981, cuyo artículo $\mathrm{N}^{\circ} 4$ establece:

"La adopción por los Estados miembros de medidas temporales especiales con el fin de acelerar la instauración de una igualdad de hecho entre los hombres y las mujeres no es considerada como un acto de discriminación tal y como queda definido en la presente Convención, pero en ningún caso debe tener como consecuencia el mantenimiento de normas desiguales o diferentes; estas medidas deben ser suprimidas en cuanto hayan sido conseguidos los objetivos en materia de igualdad de oportunidades y de tratamiento. La adopción por los Estados miembros de medidas especiales, incluidas las medidas previstas en la presente Convención, no es considerada como un acto de discriminación".

Esta Convención es el primer documento internacional que establece las discriminaciones positivas, bajo un carácter temporal, fundamentadas en el principio de igualdad. Si bien es cierto que muchas de las acciones positivas no están consagradas en una ley, numerosos/as analistas coinciden en que si éstas no están legitimadas al más alto nivel jurídico, corren el riesgo de ser anuladas, como ha sucedido en algunos países europeos ${ }^{13}$.

13. GONZÁLEZ, Yamila: "Legislación y Participación Social. Una mirada desde la Organización de las mujeres cubanas”. Curso de postgrado en la sede de la Unión Nacional de Juristas de Cuba, 2014 (Formato digital).

Facultad de Derecho y Ciencias Sociales - Universidad de Valparaíso - Chile 
En el Artículo $1^{\circ}$ de la referida Convención se define la discriminación contra las mujeres de la siguiente forma: "A los efectos de la presente Convención, la expresión "discriminación contra la mujer" denotará toda distinción, exclusión o restricción basada en el sexo que tenga por objeto o por resultado menoscabar o anular el reconocimiento, goce o ejercicio por la mujer, independientemente de su estado civil, sobre la base de la igualdad del hombre y la mujer, de los derechos humanos y las libertades fundamentales en las esferas política, económica, social, cultural y civil o en cualquier otra esfera".

Es una definición legal de lo que se debe entender por discriminación, que debe pasar a ser parte de la normativa nacional cuando el Estado ratifica la Convención. Establece que la discriminación puede revestir distintas formas: distinción, exclusión o restricción. Determina que el acto discriminatorio es aquel que tenga "por objeto" o "por resultado" la violación de los derechos humanos de las mujeres. Precisa que puede tener distintos grados, por cuanto se entiende por parcial "menoscabar" o puede ser total "anular". Precisa que puede producirse en distintas etapas de la existencia de un derecho: en el reconocimiento, el goce o el ejercicio. Define la discriminación como un acto violatorio del principio de igualdad y a la mujer como sujeto jurídico equivalente al hombre en dignidad humana, estableciendo una concepción de igualdad no androcéntrica ${ }^{14}$.

Cabe resaltar que Cuba fue el primer país en firmar la Convención y el segundo en ratificarla; ha tenido representación en el Comité de la CEDAW en casi todos sus mandatos.

En la Plataforma de Acción adoptada en la Cuarta Conferencia Mundial sobre la Mujer realizada en Beijing en 1995 se muestra una acentuada preocupación por la creciente pobreza que afecta a las mujeres, se reconoció que este fenómeno está vinculado, en algunos aspectos, al género. Se propusieron medidas encaminadas a la erradicación de la pobreza y la disminución de las desigualdades que tienen su origen en el género, entre ellas las concernientes al empleo y nivel de ingresos de las mujeres integradas al trabajo remunerado, disminución del analfabetismo femenino y fortalecimiento de la atención de salud

\section{4. Ídem.}

Revista de Ciencias Sociales - Número 68 (2016) - Universidad de Valparáíso - ISSN 0716-7725-Valparaíso, Chile 
de las mujeres. También se introdujo de una definición más amplia de la pobreza, en la que se incluyen las necesidades básicas mínimas, y también la denegación de oportunidades y opciones.

En Cuba, coherente con la favorable posición del Estado y las organizaciones e instituciones de la sociedad civil respecto a la necesidad de continuar avanzando en el marco jurídico y en la práctica de la igualdad en las relaciones de género se concede un significativo papel a las Conferencias Mundiales que han tratado el tema de la mujer, y a sus resultados, que pueden contribuir a impulsar y consolidar lo alcanzado. De ahí que, del 3 al 5 de julio de 1996 se celebró en La Habana, a propuesta de la Federación de Mujeres Cubanas (FMC), el Seminario Nacional "Las cubanas de Beijing al 2000", donde se analizó la situación de la mujer cubana a la luz de la Plataforma de Beijing, atendiendo a las características y necesidades de las mujeres de hoy, se realizó una reflexión crítica sobre los logros alcanzados y lo que aún falta por hacer para vencer los obstáculos y desafíos que tiene por delante la nación en dicho tema y la lucha contra los rezagos de una cultura discriminatoria que aún persisten en la sociedad ${ }^{15}$.

De los resultados del Seminario emanaron las propuestas que llevaron a que el 7 de abril de 1997 se adoptara por Acuerdo del Consejo de Estado de la República de Cuba y con fuerza de Ley el "Plan de Acción Nacional de Seguimiento a la Conferencia de Beijing”, cuya implementación — explícita en su contenido — es responsabilidad del Estado con la participación de todos los Organismos y el aporte de las ONG's vinculadas a este trabajo, en especial y muy particularmente la Federación de Mujeres Cubanas.

Este Plan de Acción y los dos Seminarios que con posterioridad se han realizado para evaluar la marcha de su cumplimiento, constituyen también un ejemplo tangible de la lectura de género permanente y adecuado de las políticas públicas y la legislación.

En septiembre del 2000 se efectuó la Cumbre del Milenio de las Naciones Unidas. Jefes de Estado y Gobiernos de 189 países definieron y suscribieron los llamados Objetivos de desarrollo del Milenio, a saber: erradicación de la extrema pobreza y el hambre, lograr enseñanza

15. GONZÁLEZ, Yamila: Legislación y Participación Social: ob. cit.

Facultad de Derecho y Ciencias Sociales - Universidad de Valparaíso - Chile 
primaria universal, promover la igualdad de género y el empoderamiento de la mujer, combatir el VIH/Sida, el paludismo y otras enfermedades, y desarrollar alianzas globales para el desarrollo.

Desde el inicio de su definición Cuba acogió los Objetivos de Desarrollo del Milenio, que en su inmensa mayoría ya habían sido integrados a diversas normativas jurídicas y a las políticas sociales del país.

\section{LA IGUALDAD DE GÉNERO EN LA SOCIEDAD CUBANA}

Análisis de la institucionalización jurídica de la igualdad en las relaciones de género en Cuba

Desde el triunfo de la revolución cubana en 1959 se ha otorgado un lugar privilegiado al logro de la igualdad en las relaciones de género. Ello aparece refrendado en primer lugar en la Constitución de la República de Cuba.

La Constitución de la República de Cuba, en su CAPÍTULO V, ARTÍCULO 35, establece que el Estado protege a la familia, la maternidad y el matrimonio, y reconoce en la familia la célula fundamental de la sociedad.

No menos significativo son los ARTíCULOS 36, 37, y 38 que, respectivamente, establecen que el matrimonio descansa en la igualdad absoluta de derechos y deberes de los cónyuges, los que deben atender el mantenimiento del hogar y a la formación integral de los hijos mediante el esfuerzo común, de modo que éste resulte compatible con el desarrollo de las actividades sociales de ambos; todos los hijos tienen iguales derechos, sean habidos dentro o fuera del matrimonio; y que los padres tienen el deber de dar alimentos a sus hijos y asistirlos en la defensa de sus legítimos intereses y justas aspiraciones; así como contribuir activamente a la educación y formación integral como ciudadanos.

Con todo, en el CAPÍTULO VI aparece directa y ampliamente refrendada la igualdad, en los ARTÍCULOS 41, 42, 43, y 44. En el primero de estos ARTÍCULOS, se establece que todos los ciudadanos gozan de iguales derechos y están sujetos a iguales deberes. En el

Revista de Ciencias Sociales - Número 68 (2016) - Universidad de Valparáíso - ISSN 0716-7725-Valparaíso, Chile 
segundo, que la discriminación por motivo de color de la piel, sexo, origen nacional, creencias religiosas y cualquier otra lesiva a la dignidad humana está proscrita. El tercero establece que el Estado consagra el derecho conquistado por la Revolución de que los ciudadanos, sin distinción de color de la piel, sexo, creencias religiosas, origen nacional y cualquier otra lesiva a la dignidad humana tienen acceso, según sus méritos y capacidades, a todos los cargos y empleos del Estado, la Administración Pública y de la producción y prestación de servicios.

Acto seguido se especifican una serie de derechos conquistados, a los que tienen acceso ambos géneros sin ningún tipo de distinción. Entre esos derechos se encuentran percibir salario igual por trabajo igual, disfrutar de la enseñanza y salud gratuitas a todos los niveles, así como de todas las instalaciones y servicios públicos.

Aún más categórico respecto a la igualdad de género es el ARTÍCULO 44: la mujer y el hombre gozan de iguales derechos en lo económico, político, cultural, social y familiar. El Estado garantiza que se ofrezcan a la mujer las mismas oportunidades y posibilidades que al hombre, a fin de lograr su plena participación en el desarrollo del país. El Estado organiza instituciones que facilitan a la familia trabajadora el desempeño de sus responsabilidades; concede a la mujer trabajadora licencia retribuida por maternidad, antes y después del parto, y opciones laborales temporales compatibles con su función materna; y se esfuerza por crear todas las condiciones que propicien la realización plena del principio de la igualdad.

En el CAPÍTULO VII aparecen refrendados los DERECHOS, DEBERES Y GARANTÍAS FUNDAMENTALES de todos los ciudadanos sin distinción de color de la piel, sexo, creencias religiosas, origen nacional y cualquier otra lesiva a la dignidad humana.

Coherente con lo que establece la Constitución de la República de Cuba, el Código Penal cubano (Ley No 62 de 1987, actualizada en 1997) en su TÍTULO IX. DELITOS CONTRA LOS DERECHOS INDIVIDUALES, CAPÍTULO VIII. DELITO CONTRA EL DERECHO DE IGUALDAD, ARTÍCULO 295.1. "El que discrimine a otra persona o promueva o incite a la discriminación, sea con manifestaciones y ánimo ofensivo a su sexo, raza, color u origen nacional, o con acciones para obstaculizarle o impedirle, por motivos de sexo,

Facultad de Derecho y Ciencias Sociales - Universidad de Valparaíso - Chile 
raza, color u origen nacional, el ejercicio o disfrute de los derechos de igualdad establecidos en la Constitución, incurre en sanción de privación de libertad de seis meses a dos años o multa de doscientas a quinientas cuotas o ambas".

En el inciso 2, del mismo ARTÍCULO se instituye que "En igual sanción incurre el que difunda ideas basadas en la superioridad u odio racial o cometa actos de violencia o incite a cometerlos contra cualquier raza o grupo de personas de otro color u origen étnico".

En el año 1997 se producen modificaciones en el derecho penal. Se propusieron e incluyeron en el Decreto Ley 175 del propio año, las siguientes modificaciones:

- Retomar en la legislación penal con sanciones muy severas la figura de Proxenetismo y Trata de Personas (Artículo 302) con sanciones que pueden llegar hasta 30 años de privación de libertad.

- Introducir el delito de ultraje sexual (Artículo 303) que incluye el acoso sexual (se cambió la denominación del conocido "Escándalo Público").

- Excluir toda referencia en el Código que pueda ser interpretada como acto de discriminación por razón de la orientación sexual.

- Modificar el delito de corrupción de menores y aumentar el marco sancionador (primero por el Decreto Ley 175 y posteriormente por la Ley $\mathrm{N}^{\circ} 87$ ).

Llegado a este punto cabe expresar que nos parece adecuado que en la letra de la Constitución de la República de Cuba específicamente en los incisos que refrendan la igualdad de sexos y la no discriminación por dicho motivo, debería ampliarse con la introducción de la igualdad entre personas de diferente identidad, preferencia y orientación social, y la no discriminación por tales motivos.

En comparación con etapas anteriores, las cuestiones referidas a la identidad, preferencia y orientación sexual han experimentado cambios favorables en el imaginario y la práctica social en Cuba. Nuestra sociedad es mucho más tolerante con las ideas y comportamientos 
sexuales diferentes de las que representaciones y prácticas sexistas consideran como normal.

Desde hace tiempo, en el marco de la revolución cubana, la homosexualidad dejó de ser tratada como una desviación o enfermedad sexual. Este tipo de definición peyorativa de la homosexualidad no aparece en ningún tipo de literatura actualmente usada en el sistema de enseñanza a todos los niveles, ni en los libros de medicina, prácticas médicas, y psicológicas.

Cabe resaltar que actualmente en Cuba, al más alto nivel y con un esencial papel de La Federación de Mujeres Cubanas (FMC) y del Centro Nacional de Educación Sexual (CENESEX), se debaten y promueven actitudes y comportamientos hacia la diversidad sexual más tolerantes. Ello, al igual que lo concerniente a la igualdad de derechos entre hombres y mujeres, se promueve en los programas educativos a todos los niveles de enseñanza, la televisión, y las comunidades.

Conceptos como transexualidad, bisexualidad, lesbianismo, gay, y cambio de sexo se abordan abiertamente por los medios de difusión masiva y otros agentes socializadores oficializados.

Por supuesto, no podemos negar la persistencia y reproducción, en algunos segmentos sociales, de tabúes, prejuicio, estereotipos, prácticas, y situaciones socioeconómicas desfavorables que limitan en la vida cotidiana la realización plena de la igualdad de género sin distinción de sexo, identidad, preferencia y orientación sexual.

El Código Penal; el Código de Trabajo; el Código de la Familia, la Niñez y la Juventud; entre otros instrumentos jurídicos coherentes con lo establecido en la Constitución de la República protegen los derechos de igualdad de género. El Código de Trabajo se ha adelantado favorablemente al incluir lo concerniente a los derechos laborales no sólo sin distinción de sexo, sino también de orientación sexual.

Del mismo modo el Decreto Ley 175 de 1997, modificativo del derecho penal, ha dado un paso de avance al aprobar excluir toda referencia en el Código que pueda ser interpretada como acto de discriminación por razón de la orientación sexual.

Sin embargo, Mustelier y otros autores cubanos llaman la atención acerca de algunos vacíos legales en el Código Penal que pueden contribuir al tratamiento desigual a hombres y mujeres, específicamente

Facultad de Derecho y Ciencias Sociales - Universidad de Valparaíso - Chile 
en el caso del tratamiento a la prostitución, con algunas discriminaciones hacia las féminas. Ello junto a la pervivencia de prejuicios y prácticas más o menos conscientes por parte de los sujetos que de algún modo tienen que ver con el control oficial a la problemática social, y con la aplicación de la Ley ${ }^{16}$.

Para comprender lo antes expuesto debemos subrayar que en Cuba la prostitución, o más bien la entrega directa del servicio sexual no recibe un tratamiento como delito, sino como un estado peligroso. Según el vigente Código Penal Cubano LIBRO I. TÍTULO XI. EL ESTADO PELIGROSO Y LAS MEDIDAS DE SEGURIDAD. CAPÍTULO I, ARTÍCULO 72. Se considera estado peligroso la especial proclividad en que se halla una persona para cometer delitos, sin llegar a constituir un delito, demostrado por una conducta que observa en contradicción manifiesta con las normas de la moral socialista. El ARTÍCULO 73, define que el estado peligroso se aprecia cuando en el sujeto concurre algunos de los hechos definidos como índices de peligrosidad, entre ellos la conducta antisocial. Y se considera en estado peligroso por conducta antisocial al que quebranta habitualmente las reglas de convivencia social, entre otros aspectos, porque vive como un parásito social, del trabajo ajeno o explota o practica vicios socialmente reprobables.

Pero, en el Código Penal cubano el proxenetismo, la trata de personas, la pornografía y la corrupción de menores, consustanciales en todo el mundo al fenómeno de la prostitución, son considerados delitos contra el normal desarrollo de las relaciones sexuales y contra la familia, la infancia y la juventud; y se establecen sanciones de privación de libertad, para los sujetos que incurran en dichos delitos.

Asumimos que el tratamiento jurídico a la prostitución se corresponde con los ideales y valores humanistas de la revolución cubana, su oposición a toda forma de mercantilización de las relaciones

16. MUSTELIER, Sandra: "La prostitución desde el derecho. Un enfoque de género”, Facultad de Derecho, Universidad de Oriente, Cuba, 2002. (Soporte digital). MUSTELIER, Sandra; MÉNDEZ, Mirna; PÉREZ, Ailyn: "La prostitución: ¿un fenómeno solo femenino?”. En: Revista Santiago, Universidad de Oriente, No 98. Págs. 17 y ss.

Revista de Ciencias Sociales - Número 68 (2016) - Universidad de Valparáíso - ISSN 0716-7725-Valparaíso, Chile 
sexuales y de hechos que atenten contra la dignidad humana y especialmente contra la dignidad de las mujeres.

Sin embargo, es cierto que en la interpretación y aplicación del Código Penal respecto a los sujetos en prostitución ocurren discriminaciones. Se verifica una amplia sobrerrepresentación de las mujeres en los grupos procesados por tal conducta, mientras que los hombres casi están ausentes de los procesos y medidas aplicadas.

A ello contribuye la ausencia de claridad en el Código de lo que se considera prostitución, concepto que no aparece de forma explícita y por consiguiente no se define; así como la ambigüedad del término vicios socialmente reprobables que en conjunto puede dar lugar a interpretaciones diversas. Por ello debería establecerse algún tipo de instrucción que sea más aclaratoria de dichos términos, y de que se trata de una conducta ejercida por hombres y mujeres ${ }^{17}$, a la que corresponden formas de intermediación en las que se verifica la participación de ambos sexos.

No menos importante, para comprender el tratamiento desigual a hombres y mujeres en prostitución, son las construcciones socioculturales que asignan a la mujer (Eva, pecadora) el rol de brindar el servicio sexual; y al hombre, generalmente visto como heterosexual, el rol de cliente o consumidor. También, la persistencia de ciertos prejuicios, estereotipos y tabúes sobre la homosexualidad y en general sobre los géneros que llevan a un ocultamiento de la diversidad sexual presente en la prostitución.

Algunos sujetos identifican prostitución masculina con la homosexualidad, y asumen que entre los consumidores de prostitución no hay mujeres, obvian la existencia de una prostitución bisexual y homosexual de ambos sexos que sería solicitada por una clientela sexualmente diversa.

Con todo, somos del criterio de que la perfectibilidad de las Leyes, la necesidad de profundizar en las modificaciones a su letra, en su adecuada interpretación y en las prácticas jurídicas tiene centralidad en la Revolución cubana.

17. CARMENATY, Sandra: ob. cit. CARMENATY, Sandra; MÉNDEZ, Mirna; PÉREZ, Ailyn: ob. cit.

Facultad de Derecho y Ciencias Sociales - Universidad de Valparaíso - Chile 
El Derecho de Familia y específicamente el Código ha sido perfeccionado desde su promulgación, a raíz de los cambios experimentados por las familias cubanas. Ejemplos de ello son La Ley $\mathrm{N}^{\circ} 9$ de 22 de Agosto de 1977, las modificaciones al Decreto Ley $N^{\circ} 76$ de 1984 "Sobre la Adopción, los Hogares de Menores y las Familias Sustitutas”, la puesta en vigor de la Ley No 51 de 1985, Ley del Registro del Estado Civil.

En 1963 se aprueba la ley 1.100, de la seguridad social, que amplió los beneficios a todas las mujeres madres trabadoras, garantizó el derecho a las doce semanas de licencia de maternidad al año, una hora diaria de amamantamiento a las madres de lactantes y el subsidio a aquellas que por alguna razón no pudieron acceder al parto hospitalario. Una nueva ley (1.263 de 1974) amplió la licencia de maternidad a 18 semanas, obligatoria a partir de las 34 semanas de gestación, con pago de salario seis semanas antes y 12 después del parto, con disposiciones especiales o extensiones para casos excepcionales, partos múltiples, mortalidad perinatal y complicaciones del parto y el embarazo. Esta licencia puede posteriormente extenderse de forma opcional nueve meses más, sin retribución aunque se garantiza el puesto laboral a la madre.

Un paso importante en la legislación que protege a la mujer trabajadora y respalda la igualdad entre hombres y mujeres cubanos es el Decreto-Ley N $^{\circ} 234$ de 2003 que introduce modificaciones a la Ley $\mathrm{N}^{\circ} 1.263$ de 1974. El mismo amplía el periodo de licencia de maternidad retribuida y autoriza la licencia paterna para el cuidado de los niños pequeños una vez concluido el período de lactancia materna ${ }^{18}$.

La aprobación jurídica de la licencia paterna es un avance sustancial en la posibilidad de que los hombres ejerciten en la práctica determinados roles de cuidado de los hijos pequeños, en igualdad de oportunidad con las mujeres madres. Ello contribuye aún más a que la mujer cuente con las mismas oportunidades y posibilidades jurídicas que el hombre, para realizarse y participar en el desarrollo del país.

En los últimos años, la complejidad de la sociedad cubana a partir de la crisis aún no superada, los cambios familiares, grupales, socioeco-

18. ÁLVAREZ, Mayda: "La Familia Cubana: Políticas públicas y cambios sociodemográficos, económicos y de género”. Centro de Estudios de la Mujer, La Habana, Cuba, 2004. (soporte digital).

Revista de Ciencias Sociales - Número 68 (2016) - Universidad de Valparáíso - ISSN 0716-7725-Valparaíso, Chile 
nómicos, y la concurrencia de otras regulaciones que de algún modo inciden en las relaciones familiares y sociales, en el Derecho de Familia, Civil y Penal demandan profundizar en las modificaciones en las Leyes.

En tal sentido, La comisión de "Atención a la Juventud, la Niñez y la Igualdad de derechos de la Mujer de la Asamblea Nacional del Poder Popular y la Federación de Mujeres Cubanas", han elaborado y propuesto diversos proyectos de modificaciones al Código de Familia, conjuntamente con Ministerios (Justicia; Trabajo y Seguridad Social; Educación; Salud Pública), y otras instituciones como el Tribunal Supremo Popular, la Fiscalía General de la República, y la Universidad de la Habana ${ }^{19}$.

Un documento que ha favorecido los esfuerzos de modificaciones de la Legislación, es el Plan de Acción Nacional (PAN) de Seguimiento a la IV Conferencia Mundial de Naciones Unidas sobre la Mujer celebrada en Beijing en 1995. La estructura del PAN muestra la importancia concedida a la igualdad entre los géneros, pues contiene 19 medidas referidas a Mujeres y Empleo; Mujeres y Medios de Comunicación (11); acceso a niveles superiores (9); legislación (16); derechos reproductivos y sexuales (14); e investigaciones estadísticas (6).

En cuanto a Legislación, entre los acuerdos del PAN, se encuentran los relativos a la Legislación en general. Se dirigen a la necesaria divulgación, educación y evaluación de la eficacia de la legislación relativa a la mujer.

Para el Derecho de Familia se indica trabajar por el perfeccionamiento continuo de la legislación de la legislación de familia, de modo que favorezca relaciones más armónicas, justas y equitativas entre sus miembros. También la necesidad y posibilidad de viabilizar la aplicación de procedimientos especiales de familia, en lo que se destaca la necesidad de implementar salas de familia y de un procedimiento específico familiar para que los conflictos en este ámbito se operen con

19. ÁLVAREZ, Mayda: "El derecho de familia en Cuba y su repercusión en las relaciones familiares". IV Conferencia Internacional de Derecho de Familia. Encuentro Internacional Mujer, Género y Derecho. Hotel Nacional, La Habana, Cuba, 22-26 de mayo de 2006 (soporte digital).

Facultad de Derecho y Ciencias Sociales - Universidad de Valparaíso - Chile 
la celeridad, agilidad, multidisciplinariedad y sensibilidad, que garanticen la calidad y seguridad imprescindibles ${ }^{20}$. Especial énfasis se pone en aspectos legales vinculados al programa de maternidad y paternidad responsable, la obligación de dar alimentos, la guarda y cuidado de niños y niñas.

Para el Derecho penal se propusieron modificaciones a la Legislación. En el año 1997 se incluyeron en el Decreto Ley 175 las modificaciones a la legislación penal ya mencionadas en páginas anteriores; y en respecto al Derecho Internacional, se toman acuerdos en torno a divulgación, cumplimiento de obligaciones, y participación en negociaciones internacionales.

\section{Logros socioeconómicos, educativos y culturales en las relaciones de género en Cuba}

El triunfo de la revolución cubana en 1959, abrió un proceso de profundas transformaciones que conmovieron las bases de las desigualdades de género. A lo largo de más de cinco décadas se han obtenido significativos logros en tal sentido. Logros que no pueden verse desligados de la prioridad que el Estado cubano otorga a la conservación de políticas sociales universalistas. Ello, en medio de las dificultades aceleradas y generadas por una crisis aún no superada, y de un proceso de cambios para rebasar la crisis y actualizar el modelo económico y social cubano, lo cual tiene todavía como obstáculo principal el persistente bloqueo de los Estados Unidos en un contexto internacional cada vez más complejo.

A partir del triunfo de la revolución cubana, se encauzan un conjunto de transformaciones en el ámbito económico, de la educación, la salud, la seguridad social, entre otros, dirigidas a cambiar de forma favorable e integral las condiciones de vida de toda la población sin discriminaciones por motivos de sexo, color de la piel, región, o cualquier otra. Entre esas medidas se destacan: eliminación de las relaciones de

20. ÁLVAREZ, Mayda: "El derecho de familia en Cuba y su repercusión en las relaciones familiares”. IV Conferencia Internacional de Derecho de Familia. Encuentro Internacional Mujer, Género y Derecho. Hotel Nacional, La Habana, Cuba, 22-26 de mayo de 2006 (soporte digital).

Revista de Ciencias Sociales - Número 68 (2016) - Universidad de Valparáíso - ISSN 0716-7725-Valparaíso, Chile 
explotación y las desigualdades generadas por estas, promulgación de avanzadas políticas como la gratuidad de la educación y la salud, supresión del analfabetismo, redistribución de la riqueza social a través de formas más equitativas, y el pleno empleo para hombres y mujeres.

Conforme se avanza en los resultados de tales medidas, hombres y mujeres experimentan una elevada movilidad social ascendente ${ }^{21}$.

En lo referido a la eliminación de las disparidades entre géneros en educación, es ilustrativo que en el curso 1984-1985, en los 46 centros universitarios del país, existentes en ese momento, con una matrícula total de aproximadamente doscientos ochenta mil estudiantes, el $54 \%$ de los graduados fueron mujeres ${ }^{22}$.

Se producen significativos cambios cuantitativos y cualitativos en el acceso de las mujeres al trabajo remunerado. Según informaciones aportadas en 1986 por el Partido Comunista de Cuba, en 1970 por cada 100 trabajadores 23,5 eran mujeres. Hacia 1980 se verifica un 32, 0 por cada 100, y en 1985 ascendió a 37\%. Asimismo, datos presentados por Gonzáles en 1986, demuestran que si en el censo de 1953 las actividades de los servicios ocupaban al $46 \%$ de la fuerza de trabajo femenina, en 1981 representó el 24, $4 \%$, al tiempo que las trabajadoras ubicadas en el grupo de profesionales, técnicos y administrativos de un 26,5\% ascendieron a $54,5 \%{ }^{23}$.

Se establece realmente la existencia de salario igual por trabajo igual, sin distinción de sexo, color de la piel, o de otro tipo.

21. DOMÍNGUEZ, María Isabel: "Juventud cubana: procesos educativos e integración social”. En: Cruz, Yuliet; García, Fabián; García, Celia; Fernández, Juliette: Cuadernos del CIPS 2009. Experiencias de investigación social en Cuba. Publicaciones Acuario. Centro Félix Varela, La Habana, 2010. Págs. 110 y ss.

22. SILVA, Arnaldo. "La revolución en el poder (1959-1995)". En: López, Francisca; Loyola, Oscar; Silva, Arnaldo: Cuba y su Historia. Editorial Félix Varela, La Habana, 2005. Págs. 219 y ss.

23. CATASÚS, Sonia; RODRÍGUEZ, Grisel: "Fecundidad". En: Colectivo de Autores: Cuba. Población y Desarrollo. Centro de Estudios Demográficos, Universidad de La Habana, Fondo de Población de las Naciones Unidas, 2009. Págs. 35 y ss.

Facultad de Derecho y Ciencias Sociales - Universidad de Valparaíso - Chile 
Según establece la Ley de maternidad, las mujeres integradas al trabajo remunerado que deciden ser madres se acogen a la licencia de maternidad. Cuentan, además, con la posibilidad de integrar a sus hijos pequeños a círculos infantiles y seminternados, aunque hasta la actualidad las limitaciones económicas del país condicionan que la demanda de cuidados y educación en estas instituciones supere a la oferta.

Hombres, mujeres, niños y niñas de las familias cubanas son beneficiarias de la política de acceso gratuito a los servicios de salud, considerados estos como responsabilidad del Estado. Marcaron importantes hitos en el mejoramiento de la salud de la población el reordenamiento y consolidación de la salud pública entre 1960 y 1975; su perfeccionamiento entre 1975 y 1990 se orienta a la integración de todas las acciones de salud, con énfasis en las de carácter preventivo, participación activa de las comunidades y organizaciones populares en la higiene ambiental, campañas de vacunación y educación para la salud, construcción de instituciones de salud dentro de las áreas de residencia, y desarrollo de servicios de atención con tecnología de avanzada en todo el país.

Una serie de indicadores de resultado muestran los indudables avances en la salud y que en la sociedad cubana no se verifica la precariedad y la carencia de esos servicios que afectan particularmente a los sujetos con mayor vulnerabilidad económica y cultural en algunas sociedades.

Entre 1959 y 1989 se redujo la mortalidad infantil desde 46,7 a 10,7 por cada mil nacidos vivos; la esperanza de vida se incrementó hasta alcanzar los 74 años de edad, ligeramente superior en las mujeres que en los hombres. Salvo casos excepcionales los partos se producen en instituciones hospitalarias. Las embarazadas con algún riesgo son ingresadas en una institución de salud especializada ${ }^{24}$.

Como parte del Programa Materno Infantil se realizan servicios de diagnóstico prenatal de portadores de hemofilia, Síndrome de Down,

24. DÍAZ, Elena. "Desarrollo social en Cuba: Retos y Alternativas”. En: Colectivo de Autores: Compendio de Lecturas de Temas de Administración Pública. Editorial Félix Varela, La Habana, 2013. Págs. 105 y ss.

Revista de Ciencias Sociales - Número 68 (2016) - Universidad de Valparáíso - ISSN 0716-7725-Valparaíso, Chile 
VIH/Sida, hepatitis, y diferentes malformaciones congénitas. A finales de la década de 1980, ninguna de las enfermedades transmisibles se encontraban entre las primeras diez causas de muerte de la población cubana $^{25}$.

Rupturas, continuidades, avances y desafíos en la igualdad de género en circunstancias de crisis y profundización de los cambios sociales

La década de 1990, inicia con una profunda y multidimensional crisis provocada por la conjugación de la caída del campo socialista, el recrudecimiento del bloqueo de los Estados Unidos a Cuba, y deficiencias internas.

La crisis en cuba, incluye, agravó, e hizo evidentes los síntomas de agotamiento del modelo económico extensivo, con la caída de todos los indicadores macroeconómicos. Entre 1990 y 1994 el producto interno bruto descendió entre un $36,5 \%$ y un $41 \%$; la eficiencia de las inversiones cayó de 53 a 2 centavos por pesos; se agravaron las dificultades para adquirir piezas de repuesto para la obsoleta tecnología de la industria, o para introducir nueva tecnología; el desempleo creció a más de un $7 \%$, aunque se preservó una amplia inserción al empleo, sin respaldo productivo, en entidades estatales; el severo decrecimiento de la oferta de mercancías y servicios, al no corresponderse con los ingresos de la población generó un exceso de liquidez interna ${ }^{26}$.

Las familias cubanas enfrentaron una rápida reducción de la canasta básica, y en general un deterioro de sus condiciones de vida. El consumo de calorías por habitante disminuyó de 3000 a 1900 calorías. A ello se sumó los cortes sistemáticos de electricidad, el empeoramiento del transporte, y de la infraestructura de todos los servicios públicos, la devaluación del salario real, y el incremento del desempleo ${ }^{27}$.

25. ALBIZU-CAMPOS, Juan Carlos; GARCÍA, Rolando: "Mortalidad”. En: Colectivo de Autores: Cuba. Población y Desarrollo. Centro de Estudios Demográficos, Universidad de La Habana, Fondo de Población de las Naciones Unidas, 2009. Págs. 53 y ss.

26. ALONSO, Aurelio: El laberinto tras la caída del muro. CLACSO, Argentina, 2009. Pág. 313.

27. Ídem.

Facultad de Derecho y Ciencias Sociales - Universidad de Valparaíso - Chile 
La crisis impactó a toda Cuba y de forma particularmente fuerte a las regiones orientales, históricamente más retrasadas que las del centro y occidente del país, pese a que posterior a 1959 disminuyeron las disparidades entre regiones.

La profundidad de la crisis a nivel macro, meso y microsocial, empobreció a la sociedad cubana, especialmente a sus sectores más vulnerables, o sea, sectores con cierta desventaja socioeconómica y cultural, con una escasa capacidad para enfrentar eventualidades y cambios rápidos de circunstancias. $\mathrm{Al}$ respecto, es indudable que no obstante el alcance de las políticas públicas encauzadas, su excesiva homogeneización y centralización dentro del modelo económico y social cubano consolidado durante los años de la década de 1980, incidieron en la reproducción de desigualdades configuradas histórica y culturalmente; pues no se logró "atender de forma particularizada las necesidades de sectores en condiciones de partida desventajosas, que no le permiten acceder en verdadera situación de igualdad a la apropiación de los beneficios distribuidos homogéneamente, que requerirían de acciones focalizadas que direccionaran y complementaran la universalidad" 28 .

Es sugerente que en las difíciles circunstancias socioeconómicas se le dio continuidad a políticas sociales universalistas que contribuyen a mantener altos indicadores en salud y educación; pero en los años más álgidos de la crisis, existe una sobrerrepresentación de las mujeres y especialmente de las personas no blancas en los segmentos sociales más afectados por el incremento de las enfermedades y el ligero deterioro de la esperanza de vida al nacer ${ }^{29}$.

Del mismo modo, no obstante las dificultades se logró mantener, en sentido general, los altos logros en la educación; observándose una escolarización primaria prácticamente absoluta para ambos sexos, una diminución de la escolarización secundaria hacia mediados de esa década que luego comenzó a recuperarse; y la reducción de la esco-

28. ESPINA, Mayra: Políticas de atención a la pobreza y la desigualdad: examinando el rol del Estado en la experiencia cubana. CLACSO, Argentina, 2010. Pág. 172.

29. ALBIZU-CAMPOS, Juan Carlos; GARCÍA, Rolando: ob. cit. 
larización terciaria, lo que acentuó los procesos de autorreproducción de los profesionales, y de feminización, observándose cierta fragilidad de algunas personas no blancas ${ }^{30}$.

La crisis acelera la tendencia interna a emigrar hacia otros territorios, en lo que persiste el carácter de emisor de migrantes de todas las provincias orientales; y un ligero reforzamiento en los migrantes de las mujeres y la población no blanca ${ }^{31}$, algunos de los cuales nutrieron barrios marginales, ilegales; con serias dificultades para acceder a bienes y servicios ya deprimidos para la población residente por largo tiempo, en los lugares de destino de los emigrantes.

A lo largo de los últimos veintiséis años se toman un conjunto de medidas para salir de la crisis y reinsertarse en la economía internacional, atenuar los efectos negativos de crisis y reformas, y actualizar el modelo económico cubano.

En la última década del siglo pasado, se destacan medidas como apertura al capital extranjero en formas de empresas mixtas y otras formas de asociación; prioridad al desarrollo del turismo y de la industria médico farmacéutica; control centralizado de los recursos del país; programa alimentario; reforma constitucional de 1992; despenalización de la tenencia y uso de moneda libremente convertible; dualidad monetaria y cambiaria, con una tasa oficial (un peso por un dólar) y otra en las llamadas Casas de Cambio (CADECA); apertura de tiendas para la venta de productos en divisas; activación del trabajo por cuenta propia; autorización a recibir remesas desde el exterior; entrega de tierras en usufructo para la creación de Unidades Básicas de Producción Cooperativa; creación de mercados minoritas; implantación de un sistema tributario; inicio del perfeccionamiento empresarial para el sector estatal de la economía que incluye nuevas formas de retribuciones y estimulaciones, creación de corporaciones que operan en moneda libremente convertible ${ }^{32}$.

30. DOMÍNGUEZ, María Isabel: ob. cit.

31. MOREJÓN, Blanca; SAN MARFUL, Eduardo: "Migraciones internas". En: Colectivo de Autores: Cuba. Población y Desarrollo. Centro de Estudios Demográficos, Universidad de La Habana, Fondo de Población de las Naciones Unidas, 2009. Págs. 77 y ss.

32. ALONSO, Aurelio: ob. cit.

Facultad de Derecho y Ciencias Sociales - Universidad de Valparaíso - Chile 
En los primeros años del presente siglo, sobresale la salida del dólar de la circulación interna, desde 2003-2004, y establecimiento de una dualidad monetaria, financiera y cambiaria en moneda nacional (El CUP y el CUC); y potenciación de la exportación de servicios profesionales.

Hacia el año 2008, se potencia el trabajo por cuenta propia. A partir de 2011, con la actualización del modelo económico cubano se acelera el perfeccionamiento empresarial, en lo que se trata de adecuar el empleo en entidades estatales, a sus necesidades reales de contratación de fuerza de trabajo; incremento del arrendamiento de tierras, y arrendamiento de locales propiedad del estado, a personas naturales y jurídicas; autorización de la contratación de la fuerza de trabajo(2011); autorización, con aprobación previa del Consejo de Ministros, de la formación de cooperativas en actividades no agropecuarias (2013); Nueva Ley de inversión extranjera en el 2014, que hace posible dicha inversión en toda las áreas, y la creación de empresas totalmente extranjeras, excepto en el ámbito de la salud, la educación e instituciones armadas, salvo sus sistemas empresariales; aprobación de la gestión económica por formas no estatales, en las actividades de gastronomía y los servicios técnicos y personales (2014).

Las medidas aprobadas en los años de la década de 1990 permitieron sortear los desequilibrios económicos más acentuados producidos por la crisis, detener la caída de la economía cubana e iniciar el proceso de recuperación. El resto de las medidas aprobadas posteriormente permiten sostener un modesto crecimiento económico. Y en su conjunto crecer en algunos sectores, y darle continuidad a políticas públicas y logros sociales.

Sin embargo, obviamente las medidas mencionadas transforman de las relaciones de propiedad. Junto a la predominante propiedad estatal sobre los medios fundamentales de producción en su formas tradicionales y emergentes; se amplía la propiedad del campesinado y de la cooperativa agropecuaria, se afianza la propiedad privada individual y emerge la propiedad mixta (estatal-privada extranjera) ${ }^{33}$; al tiempo que

33. ESPINA, Mayra; MARTÍN, Lucy; NÚÑEZ, Lilia: "Reajuste económico y cambios estructurales”. Temas. 3ra. época. Nº 21, La Habana, 2001. Págs. 6 y ss.

Revista de Ciencias Sociales - Número 68 (2016) - Universidad de Valparáíso - ISSN 0716-7725-Valparaíso, Chile 
en el marco de la actualización del modelo económico cubano se refuerza la propiedad privada capitalista, y la cooperativa en actividades no agropecuarias.

Consiguientemente, en la sociedad cubana en los últimos veintiséis años, se producen cambios en la estructura socioclasista, cuyos componentes, no serán solo la clase obrera, intelectualidad, directivos de empresas estales y el campesinado; ya que se amplían los trabajadores privados individuales; la burguesía, pequeña aún, urbana y rural, y con ella los trabajadores asalariados del sector privado; observándose procesos de reestratificación social, tanto a nivel social como al interior de todas las clases y grupo sociales, lo que envuelve el incremento de la desigualdades sociales ${ }^{34}$; incluidas las derivadas de relaciones de explotación, que no por ser mínimas tienen menos connotación en nuestras circunstancias.

La coexistencia en Cuba de diferentes tipos de propiedad y las continuidades, y cambios que apuntan hacia una mayor heterogeneidad en las fuentes de ocupación o empleo, y de las fuentes de retribuciones, revelan la coexistencia de diferentes fuentes de distribución de la riqueza social que son "el elemento tangible por excelencia de los esquemas de estratificación social" 35 .

Entre las fuentes de distribución de la riqueza social en la Cuba actual se destacan la distribución a través de los fondos sociales de consumo; distribución en correspondencia con la calidad, cantidad y resultados del trabajo, aún con sus distorsiones es posible ubicar en ella el salario recibido en entidades estatales tradicionales, emergentes y mixtas; esquemas de estimulación en entidades del sector empresarial, y otras; retribución por empleo en sector cooperativo y privado, e ingresos netos obtenidos por trabajo por cuenta propia; distribución a través de la apropiación de trabajo ajeno, incluidas la explotación del trabajo ajeno, lo obtenido en los márgenes de la legalidad en cualquiera de su formas; y retribuciones a través de donativos y remesas familiares ${ }^{36}$.

34. Ídem.

35. Ibídem. Pág. 11.

36. FERNÁNDEZ, Oscar: "El Modelo de Funcionamiento Económico en Cuba y sus transformaciones. Seis Ejes Articuladores para su análisis”. En: Colectivo de Autores: Compendio de Lecturas de Temas de Administración Pública. Editorial Félix Varela, La Habana, 2013. Págs. 1 y ss.

Facultad de Derecho y Ciencias Sociales - Universidad de Valparaíso - Chile 
En la sociedad cubana, pues, existen desigualdades sociales las que, según Espina, se comprueban, situándonos en su extremos, en la presencia de grupos en una situación ventajosa para satisfacer sus necesidades, entre ellos individuos y familias que tienen acceso frecuente a las remesas familiares, a ingresos salariales u otras retribuciones en el sector mixto o emergente, y algunos segmentos de los más prósperos emprendedores privados. En el otro extremo, se verifican grupos sociales con dificultades para satisfacer necesidades perentorias entre los que se encuentran personas sin ingresos fijos; familias ampliadas y monoparentales generalmente maternas, o cualquier otra, cuya manutención corre a cuenta de una sola persona o en las que nadie trabaja establemente pese a la ayuda estatal a los casos de mayor desventaja social; individuos acogidos a la jubilación y al salario mínimo; entre otros, en ausencia de redes familiares de ayuda y de recursos que le permitan acceder realmente, en condiciones de igualdad, a las oportunidades de prosperidad individual ya existentes y abiertas por las reformas ${ }^{37}$.

En el presente siglo se aceleran cambios en la estructura de los hogares y las familias cubanas, no privativos de nuestras circunstancias, y que en sí mismos no tienen una naturaleza negativa; pero en determinadas situaciones pueden contribuir a la reproducción de desigualdades de género.

En tal sentido, sobresale la aceleración de cambios que generan un reforzamiento de la coexistencia de diversas formas de hogares y/o familias, a saber: unipersonales; extendidas; compuestas; nucleares biparentales y reconstituidas con o sin hijos; monoparentales, generalmente, maternas; acompañado de un incremento de los hogares y familias dirigidos por mujeres, en la mayoría de las ocasiones en ausencia de su cónyuge o de una relación fija, lo que agrava la histórica sobrecarga sobre la mujer de las funciones domésticas ${ }^{38}$.

37. ESPINA, Mayra: Políticas de atención a la pobreza y la desigualdad, ob. cit.

38. BENÍTEZ, María Elena: "Dinámica de los hogares y de la Familia cubanos". En: Colectivo de Autores: Cuba. Población y Desarrollo. Centro de Estudios Demográficos, Universidad de La Habana, Fondo de Población de las Naciones Unidas, 2009. Págs. 181 y ss.

Revista de Ciencias Sociales - Número 68 (2016) - Universidad de Valparáíso - ISSN 0716-7725-Valparaíso, Chile 
Las desigualdades instaladas en las relaciones sociales actúan sobre hombres y mujeres. Sin embargo, algunas informaciones apuntan de un lado a que la situación de las familias cubanas, y especialmente las dirigidas por mujeres no es homogénea debido a la heterogeneidad y estratificación social más diferencias observables en los arreglos en torno a roles familiares, entre otros aspectos. Y de otro lado a que la conjugación de “...condiciones socioeconómicas y familiares desventajosas en las que ejercen algunas mujeres y aspectos de la subjetividad de los actores que protagonizan o se vinculan a estos fenómenos pueden conformar o reproducir situaciones de pobreza" 39 .

Existen evidencias de la articulación desigualdades racializadas, de clase, de género, territoriales, entre otras ya existentes en el periodo anterior a, y reproducidas por, la crisis y las reformas. Ello se constataría empíricamente en la sobrerrepresentación de negros y mestizos en actividades laborales menos cualificadas y de menor remuneración, las condiciones precarias de vivienda y entorno comunitario, el menor poder real para insertarse en condiciones ventajosas en el sector no estatal de la economía. También se observa una subrepresentación de las personas no blancas en el sector emergente de la economía, los cargos de dirección grupos sociales que emigran al exterior, y los que reciben remesas familiares; más la presencia, y retroacción, de prejuicios, estereotipos y actitudes discriminatorias más o menos conscientes que contribuyen a reproducir desigualdades racializadas ${ }^{40}$.

Justamente, a inicios del presente siglo, son profundizadas las políticas sociales universalistas en los marcos del esfuerzo de las instituciones oficiales para potenciar el desarrollo humano. Para ello se encauzaron los Nuevos Programas Sociales (de aquí en adelante NPS) que abarcaron múltiples ámbitos de la vida social, buscando el continuo avance de la sociedad, en lo que se requería corregir y atenuar algunas tendencias y problemáticas sociales como la reestratificación social, el

39. ZABALA, María del Carmen: Jefatura femenina de hogar, pobreza urbana y exclusión social, ob. cit. Pág. 15.

40. ESPINA, Mayra: Políticas de atención a la pobreza y la desigualdad..., ob. cit. ZABALA, María del Carmen: Jefatura femenina de hogar..., ob. cit. 
incremento de las desigualdades sociales, el aumento de la deserción escolar, y la autorreproducción de los profesionales.

Una de las prioridades de los NPS son los procesos educativos y ampliación del acceso de todos los sectores sociales a la educación. Como resultado de los NPS se logra reintegrar a la escuela a miles de personas de ambos sexos que no habían culminado estudios, elevar los favorables indicadores en todos los niveles de enseñanza, contrarrestar la tendencia a la concentración en las universidades de hijos de profesionales, blancos y del sexo femenino, y convertir la fuerza calificada en el principal recurso del país ${ }^{41}$.

Los NPS, incluyeron acciones para mejorar la infraestructura de los servicios de salud, educación, acceso al agua, y en general las condiciones de vida de la población cubana, afectados por el deterioro de la situación económica. Aumentaron las inversiones en la reconstrucción y modernización de escuelas, policlínicos y hospitales, redes de transporte e hidráulicas.

Además, se produjeron modernizaciones en el sistema de salud, con continuidad de los diferentes programas de diagnóstico, prevención y atención primaria; se encauzaron programas de investigación, prevención y atención comunitaria, unido al incremento de salarios, pensiones y prestaciones de la asistencia social ${ }^{42}$.

Más adelante se flexibilizan las regulaciones de construcción de viviendas particulares, se estableció la venta liberada de materiales de construcción, el otorgamiento de créditos para adquirir esos materiales y pagar la mano de obra, y para múltiples casos, de los que no pueden acceder a los beneficios de esta medida, previo estudio, se ha procedido a subsidiar la construcción de una vivienda.

Un aspecto sobresaliente dentro de los NPS es el Programa de Formación de Trabajadores Sociales. Actualmente existen en Cuba un trabajador social por cada 600 núcleos familiares, con un destacado papel en el diagnóstico, prevención y atención social a diversas problemáticas sociales.

\footnotetext{
41. DOMÍNGUEZ, María Isabel: "Juventud cubana...”, ob. cit.

42. DÍAZ, Elena: ob. cit.
} 
Asimismo, se profundizó en la protección a los grupos con mayor vulnerabilidad socioeconómica y cultural. Actualmente 112.642 núcleos familiares son protegidos por la asistencia social, dentro de los cuales 176.286 personas reciben diferentes prestaciones sociales, especialmente los servicios sociales comunitarios, tales como asistencia social a domicilio, protección a madres de hijos con discapacidad severa, alimentación en centros especializados o a domicilio. También se destacan otras políticas de amparo a personas más vulnerables, entre ellas la entrega de recursos a hogares en situaciones críticas, y facilidades de acceso a equipos para la cocción de alimentos.

Como resultado de la continuidad y profundización de políticas públicas, tal y como refleja en el 2004 el Instituto Nacional de Investigaciones Económicas (INIE), en el Segundo informe sobre el cumplimiento por parte de Cuba de los objetivos de desarrollo del Milenio: "Las disparidades entre géneros en educación ya han sido eliminadas. Existe paridad en el nivel Primario, mientras que las niñas superan a los niños en las matrículas de los niveles Secundario y Terciario (...). Estos logros se reflejan posteriormente, en el acceso de las mujeres a los empleos de calidad. Las mujeres ocuparon en el 2004 el $46 \%$ de los empleos no agrícolas...constituyeron el $66 \%$ de los profesionales y técnicos ocupados en ese año, el $71 \%$ de los ocupados en las actividades de Salud, el $66 \%$ en Educación y representaron el $51 \%$ de los investigadores" ${ }^{\prime 3}$.

En dicho Informe se refiere que “...se ha avanzado sustancialmente en el propósito de que las mujeres ejerzan el poder a la par de los hombres. Cuba ocupa el lugar 7 en el mundo y el primero en América por la representación femenina en el parlamento, con el $36 \%$ de los escaños parlamentarios ocupados por mujeres en el 2004, creciendo la participación femenina en seis puntos respecto a la anterior legislatura" ${ }^{4}$.

43. HERNÁNDEZ, Raúl; CATASÚS, Sonia: "Población y Desarrollo. El caso de Cuba”. En: Colectivo de Autores: Cuba. Población y Desarrollo. Centro de Estudios Demográficos, Universidad de La Habana, Fondo de Población de las Naciones Unidas, 2009. Págs. 142 y ss.

44. Ídem.

Facultad de Derecho y Ciencias Sociales - Universidad de Valparaíso - Chile 
La continuidad del mejoramiento de la situación educativa de las mujeres se verifica en las postrimerías de la primera década del presente siglo, pues a la par de la universalización de la educación superior ascendió la integración femenina al nivel terciario. En el 2009, las mujeres representaron el $60 \%$ de la matrícula de los centros de enseñanza superior ${ }^{45}$.

En el 2009, se verifica un ascenso de la participación femenina en el ejercicio del poder. Según el Índice de Potenciación de Género del Programa de las Naciones Unidas para el Desarrollo (PENUD) entre 109 países Cuba ocupó el lugar 29. En ese año, las mujeres constituían el $43 \%$ de los parlamentarios (cuarto lugar en el mundo), el 71, $3 \%$ de los jueces y el 73, 7 de los fiscales ${ }^{46}$.

Por otro lado, el ascenso del nivel de instrucción, calificación, e integración de las mujeres al trabajo remunerado, a las organizaciones e instituciones sociales y políticas, así como el ejercicio del derecho de disfrutar de una sexualidad no asociada a la procreación, y de controlar su reproducción; en su conjunto ha incidido en la ampliación de su autonomía, autovaloración, y facultad para determinar el momento de iniciar relaciones sexuales, establecer una relación fija del tipo que prefiera y concluirla.

Lo antes dicho, junto a otros factores, ha tenido como una de sus derivaciones la desestructuración de algunos prejuicios en torno a la virginidad, madre soltera, mujer divorciada, entre otros que en períodos anteriores al triunfo de la revolución operaban como elementos discriminatorios contra la mujer.

Otras de las derivaciones han sido cambios en las familias cubanas ya mencionados, con sus avances y retos.

En todos estos años se continúa potenciando el papel de la familia y de la comunidad como agentes activos del desarrollo social. Programas comunitarios como el impulsado por la Federación de Mujeres Cubanas (FMC) dirigidos a la mujer y su familia a través de sus Casas de Orientación ubicadas en todos los municipios del país, permiten ofrecer

\footnotetext{
45. DÍAZ, Elena. "Desarrollo social en Cuba...” ob. cit.

46. Ídem.
}

Revista de Ciencias Sociales - Número 68 (2016) - Universidad de Valparaíso - ISSN 0716-7725-Valparáís, Chile 
a las familias orientación jurídica, psicológica y pedagógica de manera gratuita; y realizar actividades de carácter educativo en las comunidades y cursos de capacitación, orientados a promover la igualdad de derechos, oportunidades y posibilidades entre mujeres y hombres.

La creación de 25 Cátedras de la Mujer, Mujer y Desarrollo y Mujer y Familia en Institutos Superiores Pedagógicos y Universidades, ha contribuido a la introducción de la perspectiva de género en la docencia e investigación, aunque todavía es insuficiente su tratamiento través de cursos, seminarios o grupos de discusión. Y es necesaria la inclusión de la perspectiva de género en los planes de estudio de las diferentes carreras.

Sin embargo, existen dificultades y retos por superar en la igualdad de género de mayor connotación como la difícil remoción de las desigualdades instaladas en las relaciones sociales. Ello a causa de las propias limitaciones de los recursos financieros del país para encauzar o respaldar acciones a gran escala, lo cual en mucho le debe al entrelazamiento de la prolongación en tiempo de la crisis, insuficientes ritmos de crecimiento económico, una situación internacional adversa y el persistente bloqueo de los Estados Unidos a Cuba.

No menos importante es el crecimiento de la importancia de los ingresos individuales y familiares para poder satisfacer adecuadamente necesidades básicas, especialmente las perentorias, a raíz de la potenciación de mecanismos de mercado, y con ellos el papel efectivo y simbólico del dinero.

Las condiciones del mercado de bienes y servicios, en el que una deficitaria oferta, domina a la demanda en la que están presentes clases y estratos sociales de acentuadas diferencias en sus capacidades de consumo, que absorbe todo lo que se oferta sea cual fuere su calidad, cantidad variedad y precios ${ }^{47}$ disminuyen los salarios, pensiones y prestaciones de la asistencia social reales, pues al tiempo que estos se han incrementado oficialmente; en el mercado, paralelamente, han aumentado, se mantienen, o disminuyen escasamente los altos precios de bienes y servicios ofertados.

47. FERNÁNDEZ, Oscar: "El Modelo de Funcionamiento Económico en Cuba..”, ob. cit.

Facultad de Derecho y Ciencias Sociales - Universidad de Valparaíso - Chile 
En el mercado laboral, la necesaria readecuación de las plantillas de diferentes entidades estatales y la introducción de normas sobre idoneidad para desempeñar una ocupación, aunque se mantienen fuertes regulaciones que protegen a los trabajadores, ha ubicado a cientos de ellos en situaciones de disponibles. No obstante el amparo, las compensaciones y el apoyo mínimo durante un tiempo, ha repercutido en la ampliación de segmentos de ambos sexos con cierta fragilidad para encontrar empleo, especialmente de aquellos menos calificados, en una peor situación económica y cultural para acceder en condiciones de igualdad a las labores mejor remuneradas en el sector estatal y no estatal.

Persisten y se reproducen grupos sociales entre los que se encuentran personas de ambos sexos y familias en desventaja socioeconómica y cultural por la precariedad de sus bienes tangibles, nivel de instrucción por debajo de la media nacional y con nula o precaria calificación laboral, que tienen dificultades no sólo para acceder en condiciones de igualdad a formas de propiedad y de gestión no estatal de la economía, sino también a créditos bancarios, viajes, contrato laboral en el exterior, y otras oportunidades abiertas con la flexibilización de los créditos bancarios, de la emigración cíclica, y de la contratación en el exterior.

$\mathrm{El}$ ascenso de los graduados de nivel terciario, especialmente en ciencias sociales y humanísticas, acentuó la contradicción entre el alto nivel de instrucción alcanzado, y las posibilidades reales de inserción en labores adecuadas al perfil y calificación; lo cual agudizó la subutilización de la fuerza de trabajo calificada ${ }^{48}$, fenómeno que afecta a los dos sexos, pero muy especialmente a las mujeres, en virtud de que estas constituyen más del $60 \%$ de los graduados universitarios.

Un aspecto a no perder de vista es la inversión de la pirámide de calificación e ingresos. Profesionales de alta calificación reciben retribuciones reales más bajas que otras profesiones menos calificadas, especialmente aquellos profesionales que viven solo del salario en entidades tradicionales, y no acceden a otras retribuciones (por remesas, colaboración, contratación en el exterior, u otras). Este fenómeno afecta a hombres y mujeres, aunque algunas de las últimas pudieran ser las

48. FERNÁNDEZ, Oscar: ob. cit.

Revista de Ciencias Sociales - Número 68 (2016) - Universidad de Valparáíso - ISSN 0716-7725-Valparaíso, Chile 
más afectadas por la sobrerrepresentación femenina en los grupos de profesionales y técnicos, así como en los grupos ocupados en actividades de Salud y Educación.

Se verifica un ascenso de la presencia de las madres solteras, - ya sea por viudez, separación o divorcio, o porque lo hayan decidido,- algunas de las cuales son adolescentes, y un significativo grupo se encuentra en la etapa juvenil de formación pre-profesional, profesional, y de posible responsabilidad laboral; una parte de todas ellas fuera de la escuela y del trabajo remunerado, dedicadas a labores del hogar; aspectos todos que pueden adquirir una alta connotación negativa especialmente, aunque no únicamente, en aquellos grupos que experimentan serias carencias económicas en lo doméstico familiar; pues la ausencia de los padres implica, con excesiva frecuencia, una baja contribución efectiva de los mismos a la manutención, y menos aún a la educación, de los hijos.

La complejización de la sociedad cubana ha generado una ampliación de contradicciones que pueden resultar en conflictos intrafamiliares, que demandan de una labor intensa y sistemática de orientación y divulgación jurídica para que hombres y mujeres conozcan sus deberes y derechos, y puedan ejercitarlos verdaderamente en la práctica. En muchas ocasiones, el desconocimiento de normas elementales, la ausencia de una orientación adecuada, el burocratismo, y el no saber a dónde acudir provocan dificultades en la solución de los conflictos que se les presentan a las personas en la vida cotidiana.

Si bien las representaciones sociales de lo femenino y lo masculino han ido cambiando paulatinamente y hoy se reconoce entre los principales atributos de la mujer cubana su condición de mujer trabajadora inteligente y creativa; aún algunos roles familiares y profesionales siguen siendo vistos desde lo tradicional, es decir lo femenino o masculino limitando en la práctica las posibilidades de desarrollo de las mujeres.

La crisis aún no superada tiene una dimensión cultural, que se manifiesta en la llamada crisis de valores en la sociedad cubana. El incremento del desfasaje entre valores objetivos, instituidos y subjetivos, y entre el deber ser y el ser en la vida real es una realidad en nuestras circunstancias. El ascenso del individualismo, el egoísmo, el arribismo,

Facultad de Derecho y Ciencias Sociales - Universidad de Valparaíso - Chile 
el burocratismo, la corrupción entre otros antivalores que se manifiestan en comportamientos y prácticas habituales de algunos individuos y grupos sociales son significativos obstáculos al avance de la igualdad en las relaciones de género.

\section{CONCLUSIONES}

En la historia legislativa cubana se ha venido produciendo una interrelación dialéctica sociedad-cuerpo legislativo desde los momentos en que se hablaba de participación de la mujer y la introducción del término igualdad, hasta la explicitación de la categoría "género" en la letra del Programa de Acción Nacional.

La presencia del enfoque de género en la legislación cubana debe de estar fundada en bases axiológicas, que correlacionen los sistemas: objetivo, instituido y subjetivo, por cuanto las determinaciones internas de toda igualdad de género son el resultado de una relación jurídicosocioeconómico-educativo-cultural-axiológica.

Los avances en la igualdad de género en Cuba no están exentos de contradictoriedad dialéctica entre el sistema de valores objetivos, instituidos y subjetivos que se manifiesta en expresiones de defensa a la igualdad plena de la mujer con posturas marginales discriminatorias que se arrastran de periodos anteriores, así como en políticas públicas que parten de un amplio reconocimiento a la igualdad de género, y realidades objetivas y subjetivas que la obstaculizan. Resulta necesario incluir en la legislación nuevas figuras que tipifiquen todas las expresiones sociales de discriminación que existen en nuestra sociedad.

\section{BIBLIOGRAFÍA}

ALBIZU- CAMPOS, Juan Carlos; GARCÍA, Rolando: "Mortalidad". En: Colectivo de Autores: Cuba. Población y Desarrollo. Centro de Estudios Demográficos, Universidad de La Habana, Fondo de Población de las Naciones Unidas, 2009.

ÁLVAREZ, Mayda: "Igualdad y Brechas de género en la toma de decisiones políticas. Cuba en el contexto latinoamericano y caribeño".

Revista de Ciencias Sociales - Número 68 (2016) - Universidad de Valparáíso - ISSN 0716-7725-Valparaíso, Chile 
En Taller Internacional y Encuentro Pre-alas Del Caribe, Ciudad de La Habana, 2006 (soporte digital).

ÁLVAREZ, Mayda: "La Familia Cubana: Políticas públicas y cambios socio-demográficos, económicos y de género”. Centro de Estudios de la Mujer, La Habana, Cuba, 2004(soporte digital).

ÁLVAREZ, Mayda: "El derecho de familia en Cuba y su repercusión en las relaciones familiares". IV Conferencia Internacional de

Derecho de Familia. Encuentro Internacional Mujer, Género y Derecho. Hotel Nacional, La Habana, Cuba, 22-26 de mayo de 2006 (soporte digital).

DÍAZ, Elena: "Mujer cubana: el proceso de participación social”. Recuperado el 3 de marzo de 2014, de http://www.dict.uh.cu/Revistas/ Flacso\%202006/VOl.\%201\%20No.2/art_EDiaz10.pdf

DÍAZ, Elena. "Desarrollo social en Cuba: Retos y Alternativas”. En: Colectivo de Autores: Compendio de Lecturas de Temas de Administración Pública. Editorial Félix Varela, La Habana, 2013.

DOMÍNGUEZ, María Isabel: "Juventud cubana: procesos educativos e integración social”. En Cruz, Yuliet; García, Fabián; García, Celia; Férnándes, Juliette: Cuadernos del CIPS 2009. Experiencias de investigación social en Cuba. Publicaciones Acuario. Centro Félix Varela, La Habana, 2010.

BENÍTEZ, María Elena: "Dinámica de los hogares y de la Familia cubanos”. En: Colectivo de Autores: Cuba. Población y Desarrollo. Centro de Estudios Demográficos, Universidad de La Habana, Fondo de Población de las Naciones Unidas, 2009.

BORON, Atilio. Tras el búho de Minerva. Editorial de Ciencias Sociales, La Habana, 2003.

CAMARGO, Juana: Género e Investigación Social. Curso de Formación en Género. Módulo 2. Instituto de la Mujer de la Universidad de

Panamá, Editora Sibauste, 1999.

Constitución de la República de Cuba. Editora Política, La Habana, 2002.

Convención para la Eliminación de Todas las Formas de Discriminación contra la Mujer. Gaceta Oficial No 19.331 de 3 de junio de 1981.

DE LA CRUZ, Silvia: "Dualidad social y sexual". En: Red Fundamentos en Humanidades, Argentina, 2005.

Facultad de Derecho y Ciencias Sociales - Universidad de Valparaíso - Chile

102 
ESCRIBÁ, Ángeles: “¿Empleadas de por vida? Peruanas en el servicio doméstico en Barcelona”. En: Revista Papers, Universidad de Barcelona, 2000.

ESPINA, Mayra: Políticas de atención a la pobreza y la desigualdad: examinando el rol del Estado en la experiencia cubana. CLACSO, Argentina, 2010.

ESPINA, Mayra; MARTÍN, Lucy; NÚÑEZ, Lilia: "Reajuste económico y cambios estructurales". Temas. 3ra. época No $21, \mathrm{La}$ Habana, 2001.

FABELO, José R.: Los valores y sus desafíos actuales. Editorial José Martí, C. de la Habana. 2011.

FACIO, Alda: "El paradigma patriarcal dominante y el derecho". CD del Evento Internacional "Mujer, Género y Derecho". Celebrado en Ciudad de La Habana, 2008.

— Federación de Mujeres Cubanas: Plan de Acción Nacional de Seguimiento a la Conferencia de Beijing. Editorial de la Mujer, La Habana, Cuba, 1997.

FERNÁNDEZ, Oscar: "El Modelo de Funcionamiento Económico en Cuba y sus transformaciones. Seis Ejes Articuladores para su análisis". En: Colectivo de Autores: Compendio de Lecturas de Temas de Administración Pública. Editorial Félix Varela, La Habana, 2013.

GONZÁLEZ, Yamila: Legislación y Participación Social. Una mirada desde la Organización de las mujeres cubanas. Curso de postgrado en la sede de la Unión Nacional de Juristas de Cuba, 2014 (soporte digital).

HERNÁNDEZ, Raúl; CATASÚS, Sonia: "Población y Desarrollo. El caso de Cuba”. En: Colectivo de Autores: Cuba. Población y Desarrollo. Centro de Estudios Demográficos, Universidad de La Habana, Fondo de Población de las Naciones Unidas, 2009.

LAGARDE, Marcela: Los cautiverios de las mujeres: madresposa, monjas, putas, presas y locas. Universidad Nacional Autónoma de México, México D.F., 2003.

__ Ley No 62 de 1987 (actualizada en 1997). Ministerio de Justicia, La Habana, Cuba, 1997 (soporte digital).

— Resolución 100 de 2015 del Ministerio de Finanzas y Precios. Gaceta Oficial No 18 Ordinaria de 2015, digital en: http:// www.gacetaoficial.cu

Revista de Ciencias Sociales - Número 68 (2016) - Universidad de Valparáíso - ISSN 0716-7725-Valparaíso, Chile 
LÓPEZ, Ixa: Violencia contra la Mujer. Ediciones Lego, San Juan, Puerto Rico, 1999.

MOREJÓN, Blanca; SAN MARFUL, Eduardo: "Migraciones internas". En: Colectivo de Autores: Cuba. Población y Desarrollo.

Centro de Estudios Demográficos, Universidad de La Habana, Fondo de Población de las Naciones Unidas, 2009.

MUSTELIER, Sandra: La prostitución desde el derecho. Un enfoque de género, Facultad de Derecho, Universidad de Oriente, Cuba, 2002. (Soporte digital).

MUSTELIER, Sandra; MÉNDEZ, Mirna; PÉREZ, Ailyn: "La prostitución: ¿un fenómeno solo femenino?”. En: Revista Santiago, Universidad de Oriente, $\mathrm{N}^{\circ} 98$.

PARELLA, Sonia: "El trasvase de las desigualdades de clase y etnia entre mujeres: los servicios de proximidad". En: Revista Papers, Universidad de Barcelona, 2000.

STAFF, Mariblanca: La perspectiva de género desde el Derecho, Rivera, Staff \& Asociados, 2000 (soporte digital).

_- Seminario Nacional de Evaluación del Plan de Acción de la República de Cuba de Seguimiento a la IV Conferencia Mundial sobre la Mujer. Federación de Mujeres Cubanas, Editorial de la Mujer, 1999.

SILVA, Arnaldo: "La revolución en el poder (1959-1995)”. En: López, Francisca; Loyola, Oscar; Silva, Arnaldo: Cuba y su Historia. Editorial Félix Varela, La Habana, 2005.

ZABALA, María del Carmen: Jefatura femenina de hogar, pobreza urbana y exclusión social: una perspectiva desde la subjetividad en el contexto cubano. CLACSO, Argentina, 2009. 